\title{
Design of Monopile Foundation for Offshore Wind Turbine
}

\author{
Tushar Raktate ${ }^{l, *}$, Rohan choudhary ${ }^{l}$ \\ ${ }^{1}$ Department of Civil Engineering, Sandip University, Nashik, Maharashtra, India
}

\begin{abstract}
Offshore wind turbines are currently considered as a reliable source of renewable energy. Prefeasibility study includs calculation of preliminary dimensions of the offshore wind turbine structure used to be perform for preliminary costing to achieve at the commercial capacity of project. The main objective of study is to perform preliminary configuration for commercial viability and approximate size of the foundation pile structure. Design nomograms and equations are derived for preliminary design of monopile founded wind turbines situated at offshore of Gujarat. Parametric studies are carried out on various configurations of hollow monopile by changing water depths and properties of soil. A nonlinear static analysis of substructure is carried out considering aerodynamic and hydrodynamic forces for various structural and soil parameters. The design of sub structure wind turbine is based on API (American petroleum institute) standards. An example problem involving the design of foundations for The proposed area is located 23-40 km seaward side from the Pipavav port at Gulf of Khambhat off Gujarat coast. The site is easily accessible from the Pipavav and Jaffrabad Port, is taken to demonstrate the proposed calculation procedure. The data used for the calculations are obtained from publicly available sources. Keywords: OWT, support structures, monopile, regression analysis, nomogram.
\end{abstract}

\section{Introduction}

Environmental preservation and an integrated perspective of energy use can be achieved by the utilization of renewable energy resources. Total Renewable energy resources account for $12.2 \%$ of India's installed capacity, with $70 \%$ contribution from wind sector. Presently, the focus is moving towards Coastal wind energy due to some favorable factors like higher wind speed, low visual intrusion and noise, easy transportation of higher capacity wind turbine, Minimum transmission costs for seashore cities, conservation of useful land and over exploitation of potential onshore sites. India currently ranks as the $5^{\text {th }}$ largest onshore wind market in the world and is yet to develop its offshore wind potential.

The MNRE (ministry of new renewable energy) has recognize the Coastal regions of Rameswaram and Kanyakumari in Tamilnadu, the gulf of Kutch and the gulf of Kambhat in the state of Gujarat, as potential zones in India for installation of OWTs. This study investigates the sub-structure design of OWT using ESLs and nonlinear analysis. The novelty in the approach lies in relating important site parameters local to the individual mill to the preliminary dimensioning of the wind turbine foundation.

Almost $75 \%$ of the OWT in Europian countries are supported due to their geological character, offshore wind foundations represent a significant part of a project's essentiel expenditure, so the optimiation of model is may leads to considerable savings. By Considering this dffrent parametrs are related to foundation technology selection. i.e.water depth, turbine class based om MW, site condition, cost, installation vessels availability and local fabrication facilities between others. Typical foundations are descibed in following fig. (1)

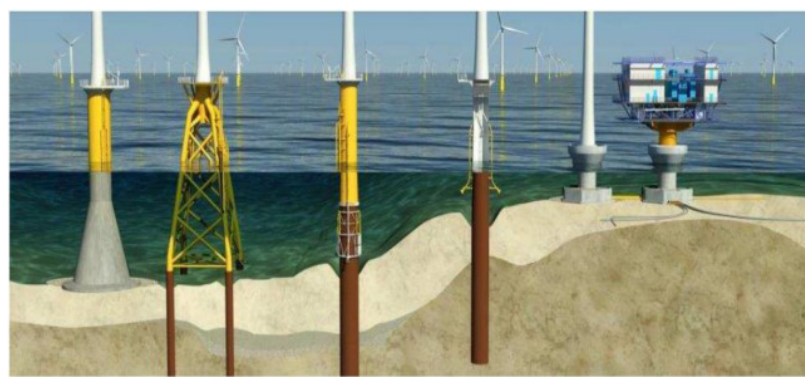

Fig. 1. Types of OWT Foundations design by COWI (From Left :(a) - Concrete gravity based, (b) - Jacket, (c/d) monopile, (e) -WTG, (f) -Gravity based Substation)

Monopile : Monopiles are used in several wind farm worldwide. This are used upto $40 \mathrm{~m}$ deep into water, and for 6-8 MW tubine capacity. Also suitable for different soil condition, and single steel pile is to be embedded into soil, which is connected to WTG through Transition piece.A monopile foundation have $50-80 \mathrm{~m}$ long steel pile of 5-8 $\mathrm{m}$ diameter of pile which is generally driven into soil.Above that "Transition Piece (TP)" is fitted, TP contains appurtenances including internal working

*Corresponding author: tusharraktate13@gmail.com 
platform, J-tube for cable protection, boat landing and much more.

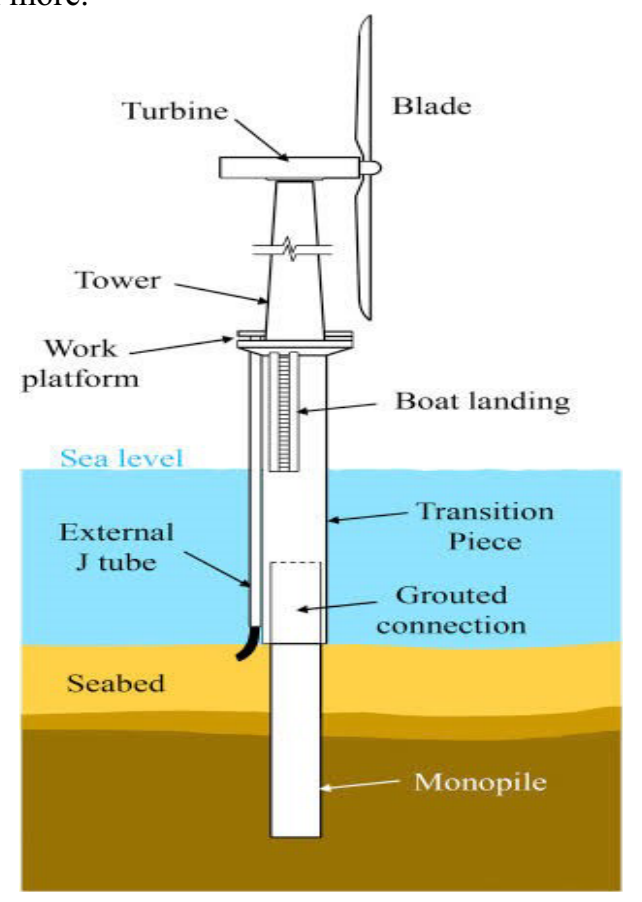

Fig. 2. Component Part of OWT

\section{Methodology}

The study involves nonlinear static analysis using SACS (structural analysis computer system) and MLRA (multivariable linear regression analysis) using statistical tools like MS Excel and Minitab.

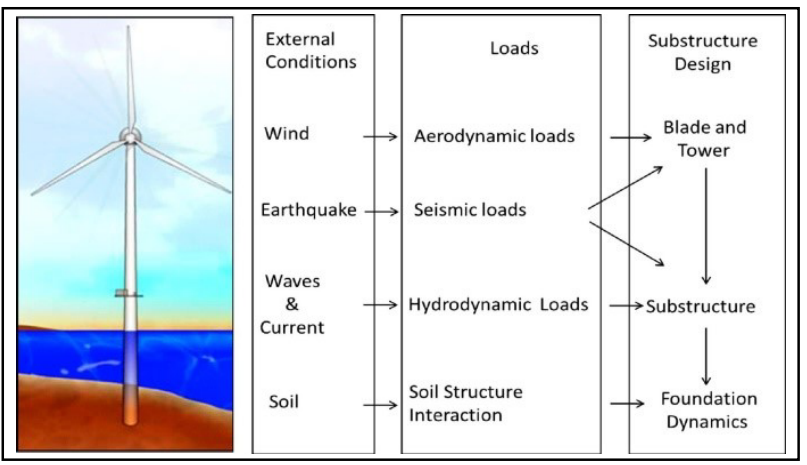

Fig. 3. Substructure design based on external condition

The substructure is design based upon (Aerodynamic, hydrodynamic and Pile-Soil Interaction). Aerodynamic load depend on site condition and turbine. In this paper Aerodynamic load are carried out by using [IEC 61400-2, (2006)] for 5MW wind turbine. The wind load on substructre and tower is estimated based on indian condition [IS 875 part 3, (2015)]. Stokes 5th order wave theory used to find wave kinematics based on water depth and wave parameters. Calculation of forces for structure is based on morison's equation for combination of wave and current. Earthquake load calculation is to be carried out by using [IS 1893 part 2, (2002)] by using response spectrum method.

\subsection{The Monopile Supported Wind Turbine Model}

The reference wind turbine used in the study is 5 MW NREL wind turbine configuration, as the data are available from the published literature NIWE and the turbine capacity is similar to those adapted in the site Gulf of khambhat gujrat. The modeling, analysis, and design are carried-out using SACS. Fig. 9 shows the SACS model of 5 MW NREL wind turbine. Homogeneous layer of silty sand is considered up-to a depth of $60 \mathrm{~m}$ from the mudline. A density $7,850 \mathrm{~kg} / \mathrm{m} 3$ for steel pile and transition piece is used in the study. Tables 1 and 2 show the properties of $5 \mathrm{MW}$ NREL wind turbine structure

Table 1: Properties of 5MW (NREL) wind turbine

\begin{tabular}{|l|l|}
\hline Rating & $5 \mathrm{MW}$ \\
\hline $\begin{array}{l}\text { Rotor orientation, } \\
\text { Configuration }\end{array}$ & Upwind, 3 Blades \\
\hline Control & $\begin{array}{l}\text { Variable speed, } \\
\text { Collective pitch }\end{array}$ \\
\hline Drivetrain & $\begin{array}{l}\text { High speed, Multiple } \\
\text { stage gearbox }\end{array}$ \\
\hline Rotor, Hub Diameter & $126 \mathrm{~m}, 3 \mathrm{~m}$ \\
\hline Height of Hub & $90(\mathrm{~m})$ \\
\hline $\begin{array}{l}\text { Cut-in, Cut-Out, Rated } \\
\text { wind speed }\end{array}$ & $\begin{array}{l}3(\mathrm{~m} / \mathrm{s}), \\
25(\mathrm{~m} / \mathrm{s}), 11.4(\mathrm{~m} / \mathrm{s})\end{array}$ \\
\hline Cut-in, Rotor speed & $6.9(\mathrm{rpm}), 12.1(\mathrm{rpm})$ \\
\hline Rated trip speed & $80(\mathrm{~m} / \mathrm{s})$ \\
\hline $\begin{array}{l}\text { Overhang, Tilt of shaft } \\
\text { and procone }\end{array}$ & $5 \mathrm{~m}, 5(\mathrm{deg}), 5.5(\mathrm{deg})$ \\
\hline Nacelle Mass & $240,000 \mathrm{~kg}$ \\
\hline Rotor mass & $110,000 \mathrm{~kg}$ \\
\hline Tower Mass & $347,460 \mathrm{~kg}$ \\
\hline
\end{tabular}

Table 2: Tower Properties

\begin{tabular}{|l|l|}
\hline Base Diameter of Tower & $6(\mathrm{~m})$ \\
\hline Base thickness of Tower & $0.028(\mathrm{~m})$ \\
\hline Top diameter of Tower & $3.86(\mathrm{~m})$ \\
\hline Top thickness of Tower & $0.018(\mathrm{~m})$ \\
\hline Modulus of Elasticity & $210 \mathrm{GPa}$ \\
\hline Modulus of Rigidity & $80.7 \mathrm{GPa}$ \\
\hline Steel density & $8,500 \mathrm{~kg} / \mathrm{m}^{3}$ \\
\hline Height above ground & $87.5(\mathrm{~m})$ \\
\hline Total mass & $347,460 \mathrm{~kg}$ \\
\hline $\begin{array}{l}\text { Structural - Damping } \\
\text { Ratio }\end{array}$ & $1 \%$ \\
\hline
\end{tabular}

\subsection{Nonlinear Static Analysis}

Wind is predominant for offshore structure. Calculation of Aerodynamic forces require information related site condition, along with wind shear and mean wind speed. The aerodynamic load on turbine are carried out by using FAST developed by NREL based on BEM (blade element momentum) theory, for standard $5 \mathrm{MW}$ NREL wind turbine. The predominant frequency for the aerodynamic thrust force is obtained through FFT (Fast Fourier Transform) for various wind conditions (Fig. 
10). Related information is taken by IEC (61400 part 32015) The aerodynamic load in time-domain is converted to ESL using DAF (Dynamic amplification factor). DAF is a dimensionless quantity which describe the number of time deflection or stress that is multiplied to deflection and stresses caused by static load when dynamic load is to be applied to the structure.
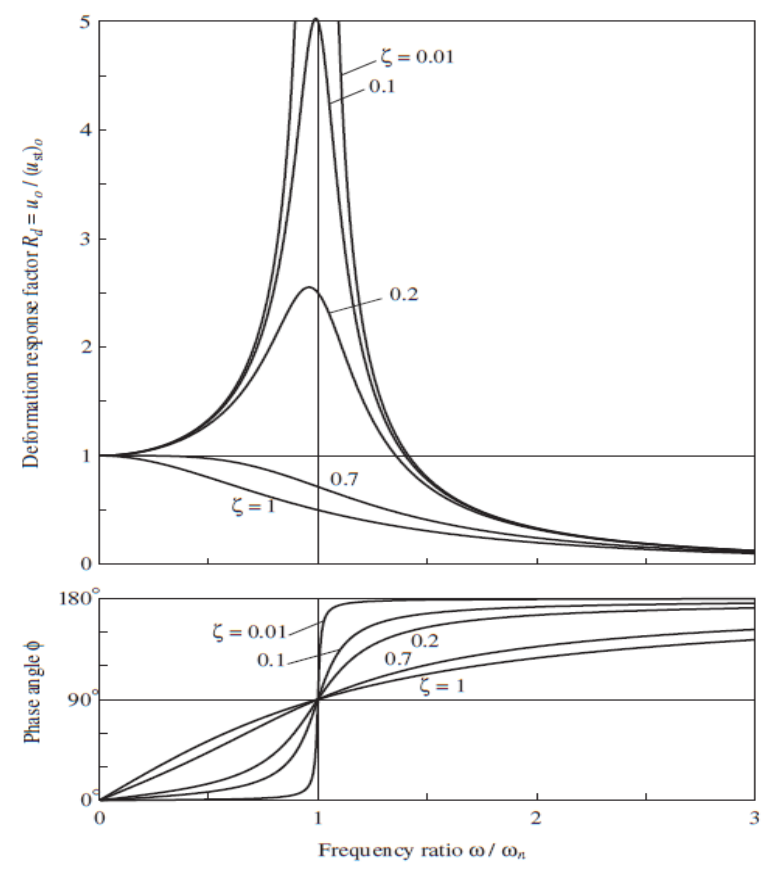

Fig. 4. DAF for damped SDOF system subjected to harmonic force.

Foe single degree of freedom subjected to harmonic motion with viscous damping, DAF is to be calculated based on following eq (1). The graphical representation of DAF vs. frequency ratio for damped Single degree of freedom is excited by harmonic force is shown in fig. (4)

$\mathrm{DAF}=\frac{X d y n}{X s t}=\frac{1}{\sqrt{\left[\left(1-\left(\mathrm{w} / w_{n}\right) 2\right) 2+\left(2 \times \in \times \mathrm{w} / w_{n}\right) 2\right]}}$

The maximum force of thrust is $1.2 \mathrm{MN}$ at the rotor level of the turbine of self weight is $3434 \mathrm{kN}$ is obtained for $\mathrm{ECD}+\mathrm{R}$ wind condition. Extreme wind speed value of $50 \mathrm{~m} / \mathrm{s}$ for gulf of Kambhat and gulf of Kutch regions is obtained using IS 875-part 3-1987 code provision. The total wind force on the tower is calculated using SACS (Connected edition) tool based on API standards.

For wind load calculation structure is divided into different geomatrical shapes and wind load on this geomatrical shape is calculated by using eq. (2)

$\mathrm{F}=1 / 2 \times \rho \times \mathrm{C}_{\mathrm{c}} \times \mathrm{U}^{2} \times \mathrm{A}$

The variation of wind intensity is generlly in time and space. Statistical wind properties like (mean wind speed and standard deviation of speed) taken over duration with 1 hour variation. The 1 hour means wind speed $\mathrm{U}(\mathrm{z})$ at height $\mathrm{z}(\mathrm{ft})$ above the sea level which is calculated based on Eqs. (3) and (4)

$\mathrm{U}_{(\mathrm{z})}=\mathrm{U}_{\mathrm{O}} \times\left[1+\mathrm{C} \times \ln \left(\frac{Z}{32.8}\right)\right] \ldots \ldots \ldots \ldots$
$\mathrm{C}=5.73 \times 10^{-2} \times\left(1+0.0457 \times \mathrm{U}_{\mathrm{O}}\right)^{1 / 2}$

The hydrodynamic load due to extreme waves of period $12 \mathrm{~S}$ and breaking wave height of 0.78 times the Water depth at site is calculated basd on Morison's equation (Eq. (5)). The equation express wave forces as a inertia forces which is proportinal to partical acceleration and a Non linear force is proportinal to square of the particle velocity.

$\mathrm{F}=\mathrm{C}_{\mathrm{M}} \frac{\rho \pi D^{2} A}{4}+\mathrm{C}_{\mathrm{D}} \frac{\rho \mathrm{Dv}|\mathrm{v}|}{2}$

Pile Soil interaction, analyzes behavior of pile supported strcture structure which is subjected to one or more static load condition. Pile finite deflecton ("Pdelta" effect) and nonlinear behavior along with directions bot transverse and longitidunal axis are considered. The program uses distributed spring type foundation model and uses finite difference technique to solve pile model which is represented beam column on nonlinear elastic foundation. Beam-column elements model structural members to resist both axial and bending actions. The structure resting above pile is represented as a linear elastic model. Soil exibits a nonlinear behavior for axial and transverse loads, therefore interactive procedure is used to calculate pile effect on deflection on structure. The analysis is generally based on the theory of subgrade reaction. The pile is discretized into segments with nodes at each end of the segments, and the soil around the pile is replaced by a series of discrete springs. Fig. 5 shows a typical pile-soil model.
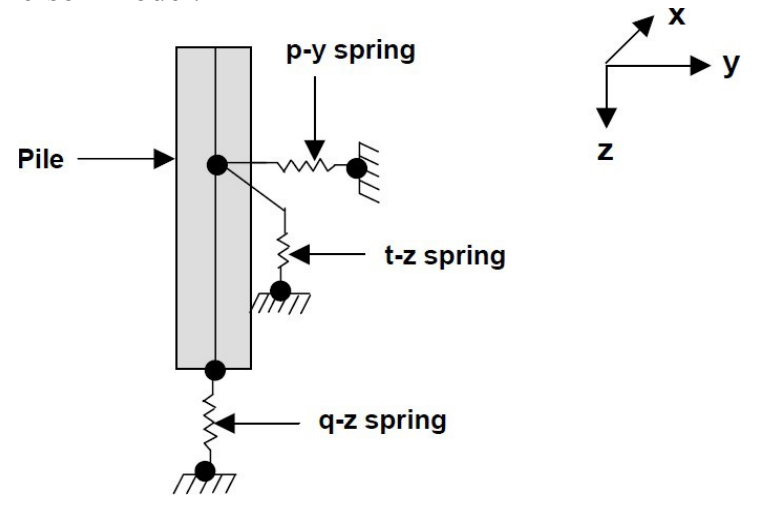

Fig. 5. Typical pile-soil model.

The equation governing the pile-soil interaction for an elastic pile (based on Bernoulli-Euler beam theory) is given in Eqs. (6) and (7).

$$
E I \frac{d^{4} y}{d x^{4}}+P_{x} \frac{d^{2} y}{d x^{2}}-p-w=0
$$

and substituting, 
$p=-k_{y}$

\subsection{Structural Design}

The analysis and design is to be carried out on 64 different models of different water depth, current velocity and angle of internal friction. The input variable used for analysis include water depth varying from $10 \mathrm{~m}$ to $30 \mathrm{~m}$, current velocity varying from $0.5 \mathrm{~m} / \mathrm{s}$ to $2 \mathrm{~m} / \mathrm{s}$ and angle of internal friction of soil varying from $25^{\circ}$ to $40^{\circ}$ (Table 3). A homogeneous layer of soil is considered throughout the length of the pile for simplicity. The output variables include diameter (D), thickness ( $t$ ), and minimum length of the pile (L). Thickness of the pile is obtained as a function of diameter, based on API standard.

Criteria of servicability is based on tolerance requirments for design of wind turbine and is described by "Turbine Manufacturer Requirements". Basically this should be turbine specific, inclusing size and hub height. Typically this tolerance are specified in some code of practice or a design specification given by client that should be given by the manufacturer. Maximum pile head rotation after installation (as per DNV-GL code) is specified with $0.25^{\circ}$ limit on "Tilt" at necelle level. Maximum rotation at pile head is limited to $0.22^{\circ}$ and the UC (unity check) ratio is limited to 0.8 .

Table 3: Design parameters

\begin{tabular}{|l|l|}
\hline $\begin{array}{l}\text { Angle of internal } \\
\text { friction of sand }\end{array}$ & $25^{\circ}, 30^{\circ}, 35^{\circ}, 40^{\circ}$ \\
\hline Water depths & $25,30,35,40(\mathrm{~m})$ \\
\hline Water height & $78 \%$ of water depth \\
\hline Wave period & $12(\mathrm{~S})$ \\
\hline Current speed & $0.5,1,1.5,2.0(\mathrm{~m} / \mathrm{s})$ \\
\hline Wind speed & $50(\mathrm{~m} / \mathrm{s})$ \\
\hline
\end{tabular}

\subsection{Statistical Analysis of Monopile foundation}

MLRA (multivariable linear regression analysis) is a statistical analysis used for calculating design parameters. It explains the linear relationship between one dependent variable (Y) and two or more independent variables $(\mathrm{X})$. multivariable linear regression analysis is generally uses least squares method to estimate the parameters. The least square method finds optimum when sum (S) of squared residuals is minimum (Eq. (8)). A residual is calculated by using difference between the actual value of the dependent variable $(\mathrm{Y})$ and the value predicted by the model (Y').

$S=\sum_{i=1}^{N}\left(y_{i}-y_{i}^{\prime}\right)^{2}$

The prediction of unknown dependent variable is accomplished by the following equation (Eq. (9)):

$y_{i}^{\prime}=b_{0}+b_{1} X_{1 i}+b_{2} X_{2 i}+\ldots+b_{k} X_{k i}$

For this study, multivariable linear regression analysis is performed on a 64 different sample size to obtain the equation or nomograms for pile diameter and for pile length. A sample size is a part of the population chosen for the study. Sample size is increases $(n \geq 30)$, shape of sampling distribution is approximately normal irrespective distribution of population. It is stated that the minimum number of samples for multiple regression analysis be at least ten times the total number of variables involved in the study.

The calculation of affected parameters for the dependent variables is based on the p-value. The predictor has low $\mathrm{P}$-value is to be addition to the model because changes in the predictor value are related to change in the response value. Conversely, a larger (insignificant) $\mathrm{p}$-value gives that changes in the predictor are not corelated with changes in the response. In other words, $p$-value indicates the probability of insignificance of a variable in the prediction model. A maximum $\mathrm{p}$ value of $5 \%$ is allowed in the model. MLRA mainly involves the following steps:

- $\quad$ Based on the data set, establish a mathematic model to estimate the unknown parameters. Least square method is a common method of estimation.

- Credibility of the obtained relations is tested by p-value of predictors in F-test of the overall significance.

- Introduce predictors with significant influence into the model, and eliminate those with no significant influence.

- $\quad$ Predict the pile outer diameter and pile length using the derived relations.

\section{Results}

\subsection{Multivariable Linear Regression Analysis}

The multivariable regression analysis is performed on the sample data using MS Excel's data analysis tool and the design equations are obtained. These equations are tested with new samples. The equation for obtaining the optimum outer diameter (D) of monopile (Eq. (10)) with coefficient of determination, $\mathrm{R}^{2}$ of $94.50 \%$ is:

$\mathrm{D}=4.252+0.0732 \times \mathrm{WD}+0.110 \times \mathrm{C}$.

where,

WD: Water depth (m)

CV: Current velocity $(\mathrm{m} / \mathrm{s})$

A equation for calculating the pile outer diameter for a given water depth and current velocity is based on the API formula (Eq. (11))

$\mathrm{t}=6.35+(\mathrm{D} / 100)$

The equation for obtaining the minimum (min.) pile length (L) of monopile (Eq. (12)) with $\mathrm{R}^{2}$ of $86.50 \%$ is:

$\mathrm{L}=56.532-1.394 \times \mathrm{SA}+1.135 \times \mathrm{MI}$. 
where,

SA: Angle of internal friction of soil (deg.)

MI: Moment of inertia $\left(\mathrm{m}^{4}\right)$

\subsection{Validation}

The predicted model is validated by using eight different cases which are taken randomly between 25-40 $\mathrm{m}$. Table 4 and 5 shows the corresponding results from SACS and predicted design equations for pile length and pile diameter.

Table 4: Validation for pile diameter

\begin{tabular}{|c|c|c|c|c|c|c|}
\hline No. & WD & CV & SA & PD1 & PD2 & Er1 \\
\hline 1 & 25 & 0.5 & 25 & 6.14 & 5.30 & -0.84 \\
\hline 2 & 27 & 0.7 & 27 & 6.31 & 5.80 & -0.51 \\
\hline 3 & 29 & 0.9 & 29 & 6.47 & 6.70 & 0.23 \\
\hline 4 & 31 & 1.1 & 31 & 6.64 & 6.15 & -0.49 \\
\hline 5 & 33 & 1.3 & 33 & 6.81 & 6.25 & -0.56 \\
\hline 6 & 35 & 1.5 & 35 & 6.98 & 6.40 & -0.58 \\
\hline 7 & 37 & 1.7 & 37 & 7.15 & 6.65 & -0.50 \\
\hline 8 & 40 & 1.9 & 40 & 7.39 & 7.15 & -0.24 \\
\hline
\end{tabular}

WD: Water depth (m)

CV: Current velocity $(\mathrm{m} / \mathrm{s})$

SA: Angle of internal friction of soil (deg)

PD1: Pile diameter using equation $(\mathrm{m})$

PD2: Pile diameter from SACS (m)

Er1: Error in pile diameter (\%)

Table 5: Validation for pile length

\begin{tabular}{|c|c|c|c|c|c|c|c|}
\hline No. & WD & CV & SA & MI & PL1 & PL2 & Er2 \\
\hline 1 & 25 & 0.5 & 25 & 5.95 & 28.44 & 26.10 & -2.34 \\
\hline 2 & 27 & 0.7 & 27 & 6.63 & 26.42 & 24.45 & -1.97 \\
\hline 3 & 29 & 0.9 & 29 & 7.31 & 24.40 & 22.30 & -2.10 \\
\hline 4 & 31 & 1.1 & 31 & 8.09 & 22.50 & 21.00 & -1.50 \\
\hline 5 & 33 & 1.3 & 33 & 8.93 & 20.67 & 15.00 & -5.67 \\
\hline 6 & 35 & 1.5 & 35 & 9.84 & 18.91 & 16.50 & -2.41 \\
\hline 7 & 37 & 1.7 & 37 & 10.81 & 17.22 & 12.40 & -4.82 \\
\hline 8 & 40 & 1.9 & 40 & 12.30 & 14.73 & 10.50 & -4.23 \\
\hline
\end{tabular}

WD: Water depth (m)

CV: Current velocity $(\mathrm{m} / \mathrm{s})$

SA: Angle of internal friction of soil (deg)

MI: Moment of inertia (m4)

PL1: Minimum pile length using equation

PL2: Minimum pile length from SACS

Er2: Error in pile length (\%)

The variation of predicted values for pile outer diameter and pile length from the mathematical model with respect to the original values from SACS analysis is represented graphically in Figs. 6 and 7.

It is seen that the predicted pile diameter values are very much close to the original values with a maximum error of $0.84 \%$. The predicted values for minimum pile length are found to be slightly deviating with that of the original results from SACS analysis with a maximum error of $5.67 \%$. This may be due to the following reasons: The assumption that the soil layer throughout the depth of the pile has the same uniform properties introduces a certain amount of error in the model. However, consideration of various soil type layers in the analysis increases the complexity of the problem by involving several parameters.

\subsection{Worked-Out Example}

Consider a location where water depth is $25 \mathrm{~m}$, current velocity of $0.5 \mathrm{~m} / \mathrm{s}$ and medium sand with angle of internal friction of $25^{\circ}$. By substituting the values in the proposed design equations, outer diameter of pile (D) and minimum pile length (L) are obtained.

$$
\begin{aligned}
& D=4.252+0.0732 \times W D+0.110 \times C V \\
& D=4.252+0.0732 \times 25+0.110 \times 0.5 \\
& D=6.140 \mathrm{~m} \\
& L=56.532-1.394 \times \mathrm{SA}+1.135 \times \mathrm{MI} \\
& M I=(\pi / 64) \times\left(\mathrm{D}^{4}-\mathrm{d}^{4}\right) \\
& M I=(\pi / 64) \times\left(\mathrm{D}^{4}-(\mathrm{D}-2 \mathrm{t})^{4}\right)
\end{aligned}
$$

Thickness of pile $(t)=6.35+(D / 100)$ with all units in $\mathrm{mm}$, based on API standards.

$$
\begin{aligned}
& \mathrm{t}=6.35+(6140 / 100)=67.75 \mathrm{~mm} \\
& =6.775 \mathrm{~cm} \\
& \mathrm{MI}=(\pi / 64) \times\left((6.14)^{4}-(6.14-2 \times 0.06775)^{4}\right) \\
& \mathrm{MI}=5.95 \mathrm{~m} 4 \\
& \mathrm{~L}=56.532-1.394 \times 25+1.135 \times 5.95 \\
& \mathrm{~L}=28.44 \mathrm{~m}
\end{aligned}
$$

Hence, a pile of outer diameter $6.14 \mathrm{~m}$, thickness $6.77 \mathrm{~cm}$ and minimum length of $28.44 \mathrm{~m}$ is required for the given site conditions. The length mentioned here is the minimum desired length to satisfy the rotation conditions.

\section{Comparision of actual value with predicted model for pile diameter}

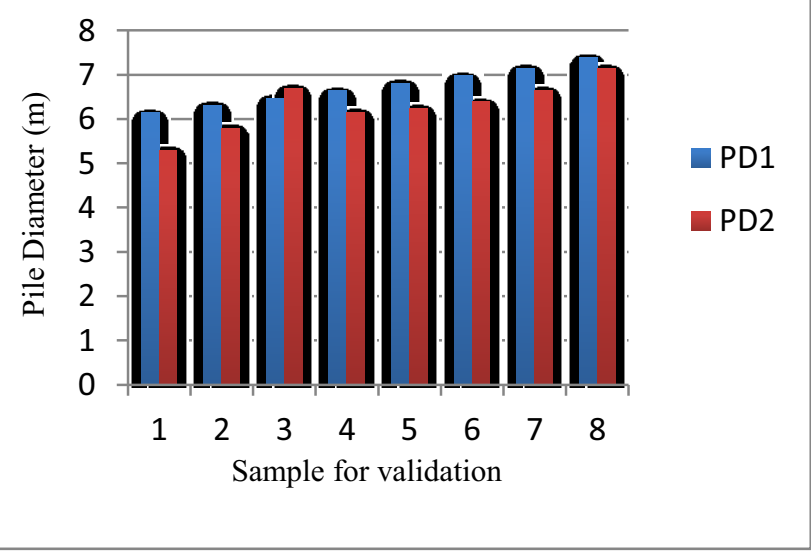

Fig. 6. Graphical representation of predicted values with actual values of pile diameter 


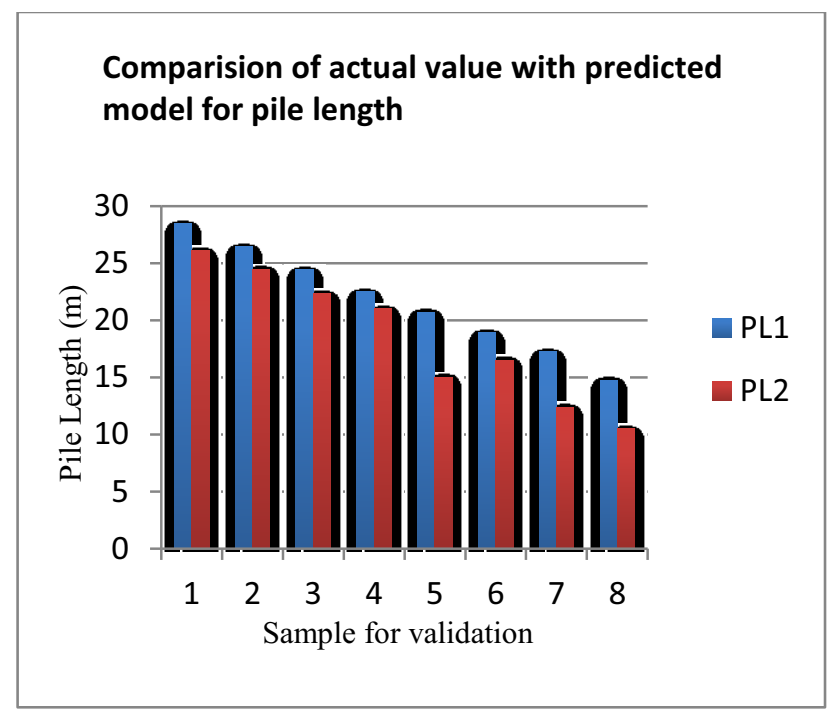

Fig. 7. Graphical representation of predicted values with actual values of pile length

\section{Conclusion}

This research study gives equations and nomograms for quick preliminary design of monopile foundation for offshore wind turbine using simple design methodology. This study is based on extreme environmental conditions of Gujarat, India. Sometimes, these equations and nomograms are useful for other site having similar environmental conditions and turbine characteristics. The obtained design equations give a clear estimate for the preliminary study on the offshore monopile design for a given site. Hence, the effort as well as time required for pre-feasibility study are reduced by this simplified design methodology. The response of monopiles under dynamic load is not properly understood and guidance in design codes is not given properly. If dynamic design is incorrect, monopile may tilt in the long term. If the tilt is greter than the allowable limit, the wind turbine may be need to shutdown. Monopile design is generally carried out by using API design procedure calibrated for flexible pile design where the pile is pretend to fail by plastic hinges. Future scope include development of prediction model by considering different layers of soil along the pile length and finite element model to generate $\mathrm{p}$-y curves for large diameter piles which are to be further involve in the monopile design for developing the prediction model. The large diameter calibrated p-y curves formulations for sand and clay under monotonic and dynamic conditions will be contribute substantially to reducing conservatism in OWT substructure design.

\section{Acknowledgement}

The authors wish to thank and acknowledge the support extended by the Sandip School of engineering and tehnology, Nashik.

\section{References}

1. "India Wind Energy Outlook." Global Wind Energy Council, (2012)

2. "Denmark Breaks its Own World Record in WindEnergy."(2016)

/.http://www.euractiv.com/section/climateenvironment/news/denmark-breaks-its-own

3. Alluri, S. K. R., Gujjula, D., Phani Kumar, S. V. S., and Ramana Murthy, M. V. "Prefeasibility Study on Fixed Platforms for Offshore Wind Turbine in India." In Proceedings of the $18^{\text {th }}$ Asia-Pacific Conference on Wind Engineering, Chennai, India. (2013)

4. A. M. David.,"Offshore Wind Market and Economic Analysis-Annual Market Assessment." Document Number: DEEE005360, U.S. Department of Energy. (2013)

5. Bhattacharya, Subhamoy. "Challenges in Design of Foundations for Offshore Wind Turbines." IET Engineering and Technology Reference, ISSN 2056-4007, (2014)

6. API recommended practice 2A-WSD (RP 2AWSD), "Recommended Practice for Planning, Designing and Constructing Fixed Offshore Platforms-Working Stress Design"

7. NIWE, "FOWPI - wind turbine, Layout and AEP" (June 2019)

8. NIWE, "FOWPI - Advisory Foundation Concept Design" (June 2018)

9. Watsamon Sahasakkul, Hieu Nguyen, Ali Sari, "An Improved Methodology for Design and Analysis of Offshore Wind Turbines Supported by Monopiles" (2016)

10. Sanjeev Malhotra, "Selection, Design and Construction of Offshore Wind Turbine Foundations structure" (2017)

11. Harvey J. Burd, Byron W. Byrne, Ross A. McAdam, Guy T. Houlsby, Chris M. Martin, William J.A.P. Beuckelaers, "Design aspects for monopile foundations " (September 2017)

12. B.C. O'Kelly, "The Offshore wind turbine foundations analysis and design" (May 2013)

13. Ishwariya Shrikanth, Satya Kiran Raju Alluri1, Krishnaveni Balakrishnan, M. V. Ramna Murthy and M. Arockisamy, "simplified design methodology for monopile foundation" (2013)

14. WILLIAM A. SCHAFFER "Monopile Foundation for Offshore Wind Turbine Simulation and Retrofitting" (2017)

15. R Damiani, K Dykes, G Scott, "A comparitive study of offshore wind support structures with monopiles and jackets for structure" (2015) 